\title{
Concerns and Challenges of Data Integration from Objective Post- Positivist Approach and a Subjective Non-Positivist Interpretive Approach and Their Validity/Credibility Issues
}

\author{
Ram Chandra Khanal \\ Corresponding Email: khanal@ sef.org.np; khanalrc@ gmail.com
}

\begin{abstract}
Integration of data derived from objective post positivist approach and interpretive non-positivist approach through mixed methods research has gained increasing attention in the recent past. But, at the same, concerns have been raised in the process of integrating data and, hence, enhancing validity/credibility of a research. This article seeks to analyze some concerns and challenges related to these aspects and provides some process to address these challenges.

This article reviewed various peer reviewed journals and other grey literatures focusing on data integration within mixed method research. The paper presents some theoretical and methodological concerns and challenges of data integration and reviews two validity/credibility frameworks. Based on these review, the paper outlines a strategy of data integration. The strategy includes selection of appropriate research methodology and data conversion processes based on the research need. The paper provides a four step process for data conversion by adopting quantitizing approach which include; creating focus questions, response coding, thematic categorizing and employing qualitative data analysis process.
\end{abstract}

Keywords: Postpositivism, interpretivism, qualitative and quantitative research approach, mixed method, data integration

\section{Introduction}

Social research is essentially concerned with exploring and understanding diverse and complex social phenomenon [26] and various world views or paradigms exist to define problems, design inquiry, interpret social realities while understanding complex social phenomenon.

There are two predominant paradigms with independent theoretical propositions. They are (post) positivism, and non-positivism or interpretivism. These paradigms represent two diverse theoretical conceptions of social realities. Positivism stands for objectivity, measurability, predictability and controllability where as non-positivism essentially emphasizes understanding and interpretation of phenomena and making meaning out of this process. A body of literature showed that the positivist approach traditionally have been considered to be investigated by using quantitative approach where as interpretive or non-positivist approach has been explained predominantly through qualitative approach.

There are, however, arguments whether such division would actually exist. Recently more and more researchers argued that the connections of these paradigms and research approaches are not necessarily in the way that it was initially thought of. It is being increasingly realized these assumptions are noticed at theoretical level where as this division is not clear and meaningful at practice level. In fact, social research is generally undertaken at continuum of (post) positivism and non-positivism which requires a good mix of both quantitative and qualitative approaches to answer the complex and dynamic research situations. 
Mixed methods have shown a strong promise that can integrate the research approaches, methos and data to answer complex social phenomenon. But there are some concerns and challenges being raized while integrating data. This necessitates for further exploration of this issue to devise strategies aiming to address the challenges so that validity or credibility of such research can be ensured.

\section{The issue}

Various scholars have discussed and debated concepts, methods, and standards of research that utilize a combination of qualitative and quantitative approaches [9]. Mix methods have been a promising option but there exist a set of challenges while integrating data received from the research approaches [5]. These challenges arguably affect the process of ensuring validity/credibility of such researches.

The validity concern has been well defined in quantitative research where as it is still ambiguous in qualitative research [18]. It is believed that a new conception of validity must be created to reconcile the well-defined (quantitative) and ambiguous (qualitative) viewpoints of the term [18]. But, this discourse of data integration and ensuring validity is emerging and no common or agreeable strategies have been prescribed so far to address these concerns in the contemporary mixed method research.

These dialogues and discussions related to data integration and validity concerns coming from the two paradigmatic routes lead to the following research questions: what are major concerns while integrating data emerged from qualitative and quantitative approaches, whether these concerns are real challenges, and is it possible to manage them by devising strategies with ensuring validity/credibility?

\section{Discussions}

The paper outlines some conceptual issues related to research paradigms and approaches, and explores concerns and challenges of data integration. The paper also discusses briefly about the validity/credibility concerns and finally proposes a set of strategies to address the challenges associated with data integration.

\section{Research paradigms}

This paradigm debate was fuelled by arguments over the nature of reality and empiricism, together with opposing views about the means for discovering reality [4]. There are many paradigms in discussion and the major ones include positivism, post positivism and constructivism and critical theory approach [15]

The positivist notion believes on a singular reality, the one and only truth, that is out there waiting to be discovered by objective and value-free inquiry [13]. It believes that reality is an externality which exists independently of human thought and perception and social complexity can be explained and predicted by investigating causal relationships between constituent elements.

Post-positivists accept that researchers' theories, background, knowledge and values can influence what is observed. However, like positivists, post-positivists pursue objectivity by 
recognizing the possible effects of biases. So, they believe that a reality exists, like positivists do, though they hold that it can be known only imperfectly and probabilistically $[15,16,27]$.

Non-positivist believes that reality is subjective, relativistic or self-referential, and non-material, and is therefore internally experienced, interpreted and constructed by the mind. Within this paradigm the individual is unique and significant (idiographic) [4]. It rejects the idea that there is single objective reality and favors subjective inquiry [13]. In essence, this paradigm is based on a relativist view of being (ontology) that holds as fundamental the premise that there exist multiple 'socially constructed realities, ungoverned by any natural laws' ([15], p.84 quoted in [24]).

\section{Research approaches}

There exist mainly three research approaches i.e. quantitative, qualitative and mixed methods. They are briefly described as below.

\section{Qualitative and quantitative research approaches}

The underlying assumption of quantitative research approach is that research designs should be based on an objective view of the world and follows the positivist model of controlling variables and testing pre-specified hypotheses. Whereas qualitative researches are carried out in natural settings, attempting to make sense of, or interpret, phenomena in terms of the meanings people bring to them. Both qualitative and quantitative researchers are concerned about the individual's point of view. Qualitative investigators believe they can get closer to the subject's perspective through detailed interviewing and observation and believe that rich descriptions of the social world are valuable.

\section{Mixed methods}

In last 3 decades, mixed method research, also known as the third wave of research approach, has become increasingly popular in educational and social science research. One reason is that the debate between pragmatism and purist are also being faded out and pragmatism has increasingly overruled purity. Now 'the question is not whether the two sorts of data and associated methods can be linked during study design, but whether it should be done, how it will be done, and for what purposes' (Miles and Huberman, 1994 cited in [1]).

Many researchers have identified strength of both qualitative and qualitative methods and argued to using them. Mixed method is, therefore, evolved on the premise of harnessing strengths of two research approaches. Tashakkori and Cresswell (2007) broadly defined mixed methods as research in which the investigator collects and analyzes data, integrates the findings, and draws inferences using both qualitative and quantitative approaches or methods in a single study or a program of inquiry. So, in mixed methods, data from both quantitative and qualitative approaches are collected, mixed and analysed.

\section{Quantitative and Qualitative Data}

Quantitative data may include closed-ended information by using a closed-ended checklist. Besides, data found in the documents such as census records are also quantitative data. The analysis of this kind of data requires statistical tools. Qualitative data, on the other hand, include 
open ended information which are gather through interview with participants or observation. The information is in words, text or images forms than in numbers. These data are analyzed typically through memoing, categorizing and thematizing with respecting diversity of ideas. It is, however, important to note that the open versus close ended nature of data does not necessarily mean that they need to originate from respective qualitative and quantitative approaches.

\section{Mixing data}

Data handling and mixing process are important concerns in data integration methods. Data management softwares have been used for quantitative data since long and new softwares are being developed which can analysed qualitative data as well. Bazeley (2006) proposed two major routes to integration when using software. They are:

- Combination of data types within an analysis, such as when categorical or continuous variables are used both for statistical analysis and as a basis for comparison of coded narrative (qualitative) material. This could occur through using both text and numeric data gathered at the same time, for example through a survey instrument; or using sequentially gathered data, most commonly; and

- Conversion of data from one type to another for analysis, typically the conversion of qualitative codes to codes used in a statistical analysis, but also, alternatively, through the contribution of quantitative data to a narrative analysis of events, circumstances, or perhaps a life history.

\section{Major concerns - data integration}

Despite several usefulness of mixing data, there are many concerns and challenges while integrating data under mixed method research. It has witnessed some theoretical and methodological challenges [5]. Some researchers argue that there exists a strong association among paradigm, methodology and methods, and integrating them into one is philosophically incompatible. Hence, combining them is logically impossible [14]. Based on this conception, qualitative and quantitative approaches or research methodology are considered to have divergent understanding on research process and data use. Bazeley (2004), for example, distinguished two types of approaches on the basis of the type of data used (textual or numeric; structured or unstructured), the logic employed (inductive or deductive), the type of investigation (exploratory or confirmatory), the method of analysis (interpretive or statistical), the approach to explanation (variance theory or process theory), and for some, on the basis of the presumed underlying paradigm (positivist or interpretive/critical). So, the concerns are at paradigmatic, methodological and data integration level.

\section{Challenges - data integration}

These paradigmatic arguments and differences between approaches pose some pertinent challenges on data integration. The first challenge is that when methods are mixed without careful consideration of the particular assumptions and expectations regarding their conduct, corruption of those methods can occur and results obtained by them become subject to question [1]. To be precise, inferential statistics, which is used to analyse quantitative data, are based on an assumptions of random selection of samples, and error rates are proportional to sample size. Besides, sample size determines the types of statistical procedures. On the basis of these, results 
are drawn which can be used to generalise to a larger population. But, in case of qualitative techniques, data is derived normally from small number of sample size which is drawn on purposive basis. Technically, the data emerging from qualitative data cannot be kept on par with quantitative data for statistical analysis and generalization.

Secondly, the priority given for types and nature data in two methods are also different. For example statisticians often dismiss 'outliers' from their analysis, and rely on probability estimates to deal with variation across the sample where as in a qualitative approach the researcher uses variations (such as outliers) to illuminate developing theories and modifies theory to take account of exceptions (Barbour, 1998 quoted in [1]).

Thirdly, quantitative approach generally depends on scientific assessments and objectivity where as qualitative follows experiential 'bottom-up' interpretive information and they generally do have multiple variations in its form and presentation of information (such as table, figures vs long narratives and nuanced interpretations) making it difficult to combine during analysis and interpretation

Due to these all these concerns and challenges, some researchers view that it is not easy to integrate data as they represent divergent paradigms with different nature of data, logics, investigation approach and explanation approaches. Due to these reasons, mixed methods research was heavily attacked by some methodologists [1].

\section{Opportunities - data integration}

Researchers argue the theoretical assumptions are just a philosophical debate based on abstract conception. For [3], it is difficult to sustain these philosophical differences in practice because qualitative and quantitative analysis techniques do not necessarily reflect a particular view of the nature of reality, how to research, or determine the truth value of data. After these debates and using them in practice, a general thinking of the assumption that working with numbers and statistics has a positivist perspective has been changed. It is increasingly recognized that there are no direct or exclusive correspondences between paradigms, methodology and methods. Hence, Morse (1991) argued that research methodologies are merely tools, instruments to be used to facilitate understanding.

There are several highlights of 'complementarity' between quantitative and qualitative techniques in educational/social science studies after the emergence of mixed method research. Studies revealed that 'one is incomplete without the other'. Danziger and Kraemer (1991), for example, argue that survey research (quantitative) and fieldwork (qualitative) have always been alternative rather than competing sources of evidence and ideas.

Data integration is now considered as an opportunity and several merits have been noted. Collins, Onwuegbuzie, and Sutton (2006), for instance, gave four rationales for mixing approaches. They include: participant enrichment (the mixing of quantitative and qualitative techniques to optimize the sample, such as increasing the sample size), instrument fidelity (maximizing the appropriateness and/or utility of the instruments used, whether quantitative or qualitative), treatment integrity (mixing quantitative and qualitative techniques to assess the fidelity of interventions, treatments, or programs), and significance enhancement (mixing quantitative and qualitative techniques to maximize researchers' interpretations of data). 
In addition, the strength of the mix method is that it provides data upon which stronger inferences can be made by capturing and presenting a greater diversity of viewpoints. Integrated data can provide a deeper, richer and more comprehensive set of data to develop effective knowledge base or evidences. It is increasingly believed that no single method can adequately capture complex understanding of any context; hence, multiple perspectives are paramount to understand complex research situations.

\section{Validity/credibility- data integration}

The concerns and challenges associated data integration processes have increased further pressure on ensuring validity/credibility of a research. Internal and external validity, reliability and objectivity are the terms used in conventional quantitative based research and many standards have been set to ensure validity of a research. But, validity or credibility issue in qualitative research is still a unclear and ambiguous concept [11], but some terms such as Credibility, transferability, dependability and confirmability are being used to describe the equivalent criteria implicitly and routinely in much participatory field research [22].

Now the question is how the validity or credibility of a research in given challenges can be promoted? The Validity issues while integrating data in mixed methods research are in their infancy mainly due to the on-going debate of paradigmatic war and types of languages conventionally being used in these research traditions.

The issue has been dealt by some researchers including [19], [17], [11], and [18] in order to find out some common approach to enhance validity or credibility of a research. But still common understanding on this issue has yet to be made. It has been difficult to devise a common approach or strategies so that external, internal, construct and conclusion validity can be ensured while integrating data from two research approaches.

\section{Validity/credibility frameworks for data integration}

A typology of mixed methods 'legitimation' was offered by [19] in order to use a bilingual nomenclature that can be used by both quantitative and qualitative researchers. They proposed nine elements in legitimation model. This model focuses on how well a researcher has to integrate the various design and inference aspects of a mixed methods study to address validity/credibility of the qualitative and quantitative segments of a mixed methods study. According to [11], the model defers to current norms or criteria of validity, which were traditionally used in quantitative and qualitative research, and provides meaningful criteria for assessing issues associated with mixed methods research. The description of each aspect is given in the following table (table 1). 
Table 1: Typology of Mixed Methods Legitimation Types

\begin{tabular}{|c|c|}
\hline Legitimation Type & Description \\
\hline $\begin{array}{l}\text { Sample } \\
\text { Integration }\end{array}$ & $\begin{array}{l}\text { The extent to which the relationship between the quantitative and qualitative } \\
\text { sampling designs yields quality meta-inferences. }\end{array}$ \\
\hline Inside-Outside & $\begin{array}{l}\text { The extent to which the researcher accurately presents and appropriately } \\
\text { utilizes the insider's view and the observer's views for purposes such as } \\
\text { description and explanation. }\end{array}$ \\
\hline $\begin{array}{l}\text { Weakness } \\
\text { Minimization }\end{array}$ & $\begin{array}{l}\text { The extent to which the weakness from one approach is compensated by the } \\
\text { strengths from the other approach. }\end{array}$ \\
\hline Sequential & $\begin{array}{l}\text { The extent to which one has minimized the potential problem wherein the } \\
\text { meta-inferences could be affected by reversing the sequence of the } \\
\text { quantitative and qualitative phases. }\end{array}$ \\
\hline Conversion & $\begin{array}{l}\text { The extent to which the quantitizing or qualitizing yields quality meta- } \\
\text { inferences. }\end{array}$ \\
\hline $\begin{array}{l}\text { Paradigmatic } \\
\text { mixing }\end{array}$ & $\begin{array}{l}\text { The extent to which the researcher's epistemological, ontological, } \\
\text { axiological, methodological, and rhetorical beliefs that underlie the } \\
\text { quantitative and qualitative approaches are successfully (a) combined or (b) } \\
\text { blended into a usable package. }\end{array}$ \\
\hline Commensurability & $\begin{array}{l}\text { The extent to which the meta-inferences made reflect a mixed worldview } \\
\text { based on the cognitive process of Gestalt switching and integration. }\end{array}$ \\
\hline $\begin{array}{l}\text { Multiple } \\
\text { Validities }\end{array}$ & $\begin{array}{l}\text { The extent to which addressing legitimation of the quantitative and } \\
\text { qualitative components of the study result from the use of quantitative, } \\
\text { qualitative, and mixed validity types, yielding high quality meta inferences. }\end{array}$ \\
\hline Political & $\begin{array}{l}\text { The extent to which the consumers of mixed methods research value the } \\
\text { meta-inferences stemming from both the quantitative and qualitative } \\
\text { components of a study. }\end{array}$ \\
\hline
\end{tabular}

Source: [19]

Dellinger and Leech (2007, p.322) also proposed a validation Framework (VF) for ensuring validity/credibility in mixed method. The VF presents a useful and unified method to frame the idea of validity in mixed methods research and to provide a guide for organizing the necessary evidence needed to support data meanings. The framework uses traditional concepts from the quantitative and qualitative traditions and also added the newer ideas. Mixed method validity framework includes various aspects by categorizing into design quality, legitimation, and interpretive rigour. The VF also include elements that have not been mentioned previously in the literature and they include foundational elements (researchers' prior understanding of a construct and/or phenomenon under study), inferential consistency (whether the inferences in a study are consistent given what is known from prior understandings, past research, and theory), utilization/historical element (extent of utilization of findings) and consequential element (consequence of use of findings or measures). The VF has considered the broader aspects of the research and also considers the utility of findings and consequences of use of finding.

These broader frameworks provide a useful basis to identify an appropriate methodological design, data collection methods, data collection and analysis process. The aspects proposed in the framework also considered all form of validity such as external, internal, construct and 
conclusion. So, adequate consideration of these aspects would enable to increase validity/credibility of a research.

\section{Strategies for addressing the challenges of data integration}

The review showed that there is no big and unmanageable issues of data integration from philosophical point of view as most of the researchers now believe that paradigmatic debates do not preclude integrating methods and data. Challenges related to data integration can be managed through the process of clarifying conceptual issues related to paradigms.

But, it is important to address challenges of data integration at methodological and operational level by identifying some appropriate measures. There are, however, many challenges at various levels of data integration in mixed method research and this is not possible to deal all those issues in the paper. Due to limited scope of this assignment, the paper will only focus on concurrent research design and 'conversion' type of data integration in the following chapter. The review showed the following prominent strategies for appropriate integration of data are important to ensure research validity/credibility.

\section{Selection of appropriate research methodology/design}

Selection of appropriate research methodology is very important strategy which determines nature and types of data collection, process of data collection, data integration process and data analysis $[2,12]$.

Various methodological approaches have been proposed within mixed research. Creswell, Plano Clark, Gutmann, and Hanson (2003) classified mixed methods designs into two major categories: i.e. sequential and concurrent (cited in [6]) where as [8] proposed six types of mixed methods designs and they include sequential explanatory, sequential exploratory, sequential transformative, concurrent triangulation, concurrent nested and concurrent transformative.

In sequential designs, either qualitative or quantitative data are collected in an initial stage, followed by the collection of the other data type during a second stage. According to [8], the data analysis typically proceeds independently for both the quantitative and qualitative phases. Researchers rely on standard data analysis approaches (e.g., descriptive and inferential analysis of quantitative data, coding and thematic analysis of qualitative data).

In contrast, concurrent designs are characterized by the collection of both types of data during the same stage although priority may be given to one form of data over the other. The purpose of concurrent triangulation designs is to use both qualitative and quantitative data to more accurately define relationships among variables of interest. In concurrent nested designs, both qualitative and quantitative data are collected during the same stage, although one form of data is given more weight over the other. The transformative design is related to change one form of data into another so that the data collected by mixed methods designs can be merged.

In this case, the analysis requires some data transformation so as to integrate and compare dissimilar databases (e.g., quantitative scales are compared with qualitative themes, qualitative themes are converted into scores) [8].

Castro et al (2010) proposed an integrative mixed method paradigm based on parallelism. In this approach integration begins with a 'unified conceptualization' of information as 'research 
evidence'. This basic design has six stages and they include (a) design (parallelism in study development), (b) data collection (evidence gathering), (c) processing/conversion, (d) data analyses, (e) interpretation, and (f) integration (figure 1).

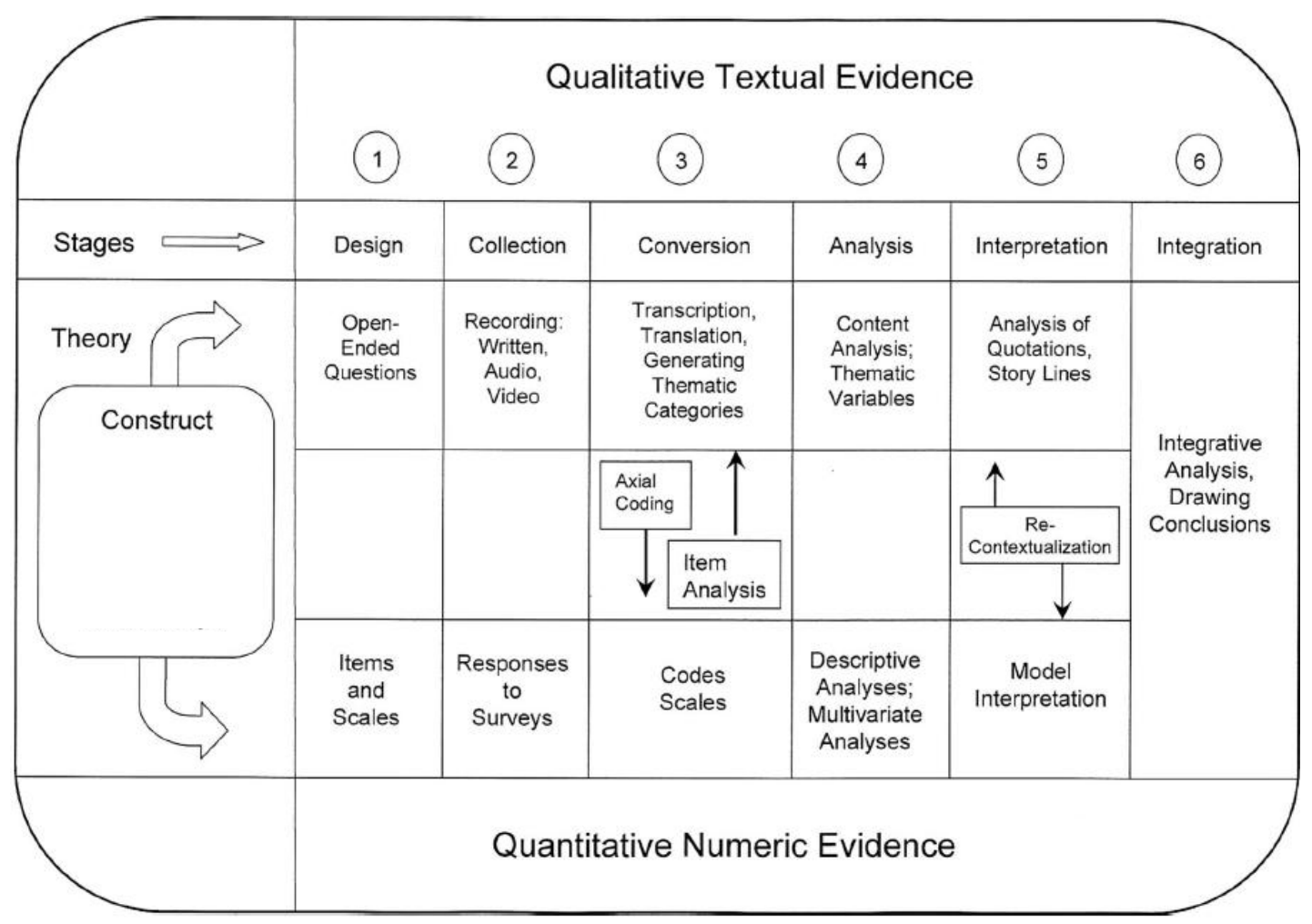

Figure 1: An integrative mixed methods design

(Source: [6])

This design allows 'seamless' data conversions and a rich interpretation of the quantitatively derived results [6]. This type of logical based parallel process helps to minimize the risk of ad hoc and unplanned data integration. Plano Clark et al., 2008 argued that the greater the qualitative-quantitative parallelism that is designed a priori into a study, the easier to transform, transfer, and interpret textual and numeric data forms across modalities. The various aspects or constituents of validity issues are to be integrated while designing and managing this research process.

\section{Data integration}

In addition to consideration of research methodology and validity aspects, it is equally important to have appropriate data management in the mixed research. Data conversion and combination are major strategies for data integration in mixed method research. Data conversion strategy through quantitizing approach is elaborated as below.

Conversion of data is about transforming one type of data to another type. This can be qualitizing (transforming quantitative data to qualitative form) and quantitizing (transforming qualitative data to quantitative form). The mostly used process is quantitizing which means 
transforming qualitative data into quantitative form to make the data amenable for statistical assimilation. In other words, quantitizing refers to the process of assigning numerical (nominal or ordinal) values to data conceived as not numerical (Sandelowski, 2009).

Castro et al., 2011, provided a methodological steps for quantitizing data and they include:

- eliciting verbal responses to a specific focus question,

- identifying response codes,

- creating thematic categories (families), and

- converting these categories into thematic variables.

Based on the review of available literature including [23], Castro et. al. (2011), [12], and Bazeley (1999) following steps can be suggested for appropriate data integration which is also shown in figure 2.

\subsection{Creating focus questions}

Unlike content analysis, research is design to create a set of focused questions which can be easily converted in to response code. For this, two types of questions can be prepared. The first one is designing the questions with open ended questions with options but focused narrowly. Once an answer is received, appropriate code for the answers is given.

Another type of question is to standardized questionnaire responses to assigned numerical values via designation of verbal anchors, for example, $0=$ never, $1=$ rarely, $2=$ sometimes, $3=$ most of the time, $4=$ always. This also based on the preference of participants which is linked to choice theory. In this approach, the objectivity attributed to their numerical precision inescapably rests on subjective decisions made by the researchers designing the questionnaires and the participants who are asked to choose the verbal anchor that best represents their experience of the target phenomenon (for detail see [23]).

\subsection{Response coding}

Coding or categorising of data is undertaken to facilitate understanding and retrieval of information for analysis. Codes are the means by which data are transferred from one format into another, or between qualitative data analysis (QDA) and statistical software [1].

Once the response set is available, appropriate coding is given based on the nature, scale and types of responses. The coding is prepared based on the requirement of research study. The coding range can be dependent on the richness of information received during the data collection or range of options given to participants. 


\subsection{Thematic categorization}

These response coding can be analysed by two methods. The response coding can be further synthesized by categorizing into thematic categories and thematic variables as mentioned by [6] or data can be directly analysed at response code level [12]. A common strategy is to count the number of times a qualitative code or thematic variables occur while analysis [12].

\subsection{Qualitative Data Analysis (QDA)}

Generally statistical data have been analysed using computer softwares where as 'in-depth' text data is analysed without. But, recent developments in computer software for qualitative data analysis (QDA) have brought about a revolution in textual analysis. Software programs allow qualitative researchers to process a large volume of qualitative data effectively (Bazeley, 1999) as they enhance ability to export coding information in tabular form.

Beside, software allows for generation of new codes as analysis is progressing, for rearrangement of codes without loss of data if the a priori codes are not sufficient. Some software provide opportunity to move from coding to categories and adjustments such as categorizing, recategorizing can be made as per the requirement in order to meet needs of statistical analysis. These differences may, however, become an issue if a researcher is determined to have a common coding system across data types in order to force comparability of conclusions from the different data sources [1], so this has to be carefully handled.

Such quantitized frequencies can show particularly influential codes and these quantitized data can be statistically compared to the quantitative data collected separately. For example, [12] used QSR NVivo2 to transform individual responses to open-ended survey and interview questions into a series of coded response categories that were, in turn, quantified as binary codes and integrated into the associated survey responses. This process involved following (four) analytic steps:

1. The survey data were entered into an Access database.

2. The qualitative data were analyzed for codes or themes using NVivo. These codes were then developed into qualitative response categories that were entered into a second Access database.

3. These two databases were linked by key informant identification numbers to ensure that each record contained both the survey and in-depth interview data.

4. The coded qualitative data were then quantified into dichotomous variables 0 or 1 based on absence or presence of each coded response.

5. Associations were analyzed using SAS. 


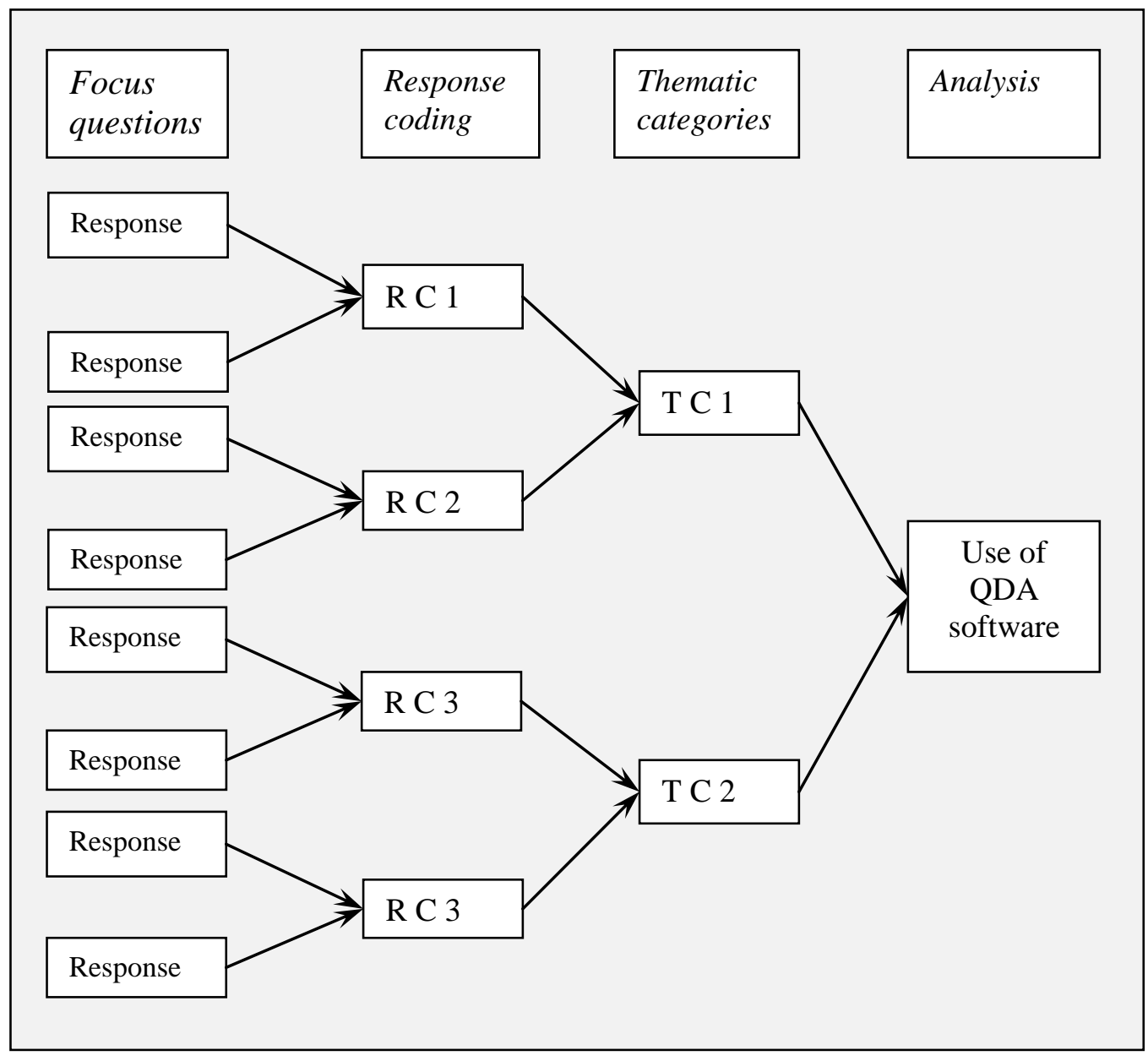

Figure 2: Data integration process in mixed method

(Source: Adapted from [6])

By adopting an appropriate research methodology/design and steps for safe integrating data with consideration of validity/credibility issues can address methodological challenges and help to increase the conformational power of a research.

\section{Summary and Conclusions}

The purpose of this paper is to explore on concern, challenges, opportunities and validity/credibility issues related to data integration originated from post positivist and nonpositivist paradigms in order to ensure validity/credibility in such mixed type of research. Mixed methods designs can provide pragmatic advantages when exploring complex research questions through the blending of two types of methodology, methods and data.

A body of literature revealed arguments and counter arguments whether methodology, methods and data can be integrated. There are basically two concerns put forward by many researchers. The first one is quantitative and qualitative data basically represent post/positivist and nonpositivist/interpretive philosophy respectively and it is not possible to merge these philosophies 
into one. In addition, they also argue the type of data and nature of analysis of those data are based on different assumptions, so merging data is not possible at operational level.

There is, however, another school of thought which argues data integration is possible in mixed method research and this is becoming very popular in recent days. Mixed method research has been developed in such as way that can manage these challenges. They further viewed that there is no clear connection between philosophies and research method and, in fact, researchers need to employ both methods for a research in order to solve practical problems.

Ensuring validity/credibility of mixed method in this context has also been an issue due to divergent assumptions and understanding between the research approaches. There has been some endeavor to address these issues. Onwuegbuzie \& Johnson (2006) have proposed a 'legitimation' model which includes nine aspects that helps to increase validity/credibility. Similarly, [11] proposed a unified Validation Framework comprising of traditional concept of qualitative and quantitative techniques and new ideas appropriate for addressing integration of data from these research traditions. These legitimation aspects and other constructs mentioned in these frameworks have to be maximized by involving the community of quantitative and qualitative scholars in order to address validity/credibility concern of a research.

Based on the challenges, opportunities and validity issues of data integration available in the literatures, two strategies has been proposed. The first one is to adopt an appropriate research methodology in order to provide an opportunity to define data collection process and extent of data integration on a priori basis where as the second strategies is to integrate data at operation level. For concurrent research design, data conversion through quantitizing approach can be adopted and specific steps include creating focus questions, preparing response questions, thematic categorization and follow QDA.

In summary, integration of data from different paradigmatic routes has some concerns and challenges but they can be managed by having some strategies in place. Hence, by synergizing the strength of quantitative and qualitative approaches, data integration can be a good opportunity for solving complex social problems.

\section{References}

[1] Bazeley, P. (2004). Issues in Mixing Qualitative and Quantitative Approaches to Research. In R. Buber, J. Gadner, \& L. Richards (eds.), Applying qualitative methods to marketing management research. UK: Palgrave Macmillan, 141-156.

[2] Bazeley, P. (2006). The Contribution of Computer Software to Integrating Qualitative and Quantitative Data and Analyses, Research in the Schools, 13 (1), 64-74.

[3] Bergman, M. M. (2010). On Concepts and Paradigms in Mixed Methods Research, Journal of Mixed Methods Research, 4 (3), 171-175. DOI: 10.1177/1558689810376950.

[4] Bisman, J. (2010). Postpositivism and Accounting Research: A (Personal) Primer on Critical Realism, Australasian Accounting Business and Finance Journal, 4(4), 3-25. Available at: http://ro.uow.edu.au/aabfj/vol4/iss4/2.

[5] Bryman, A. (2007). Barriers to Integrating Quantitative and Qualitative Research, Journal of Mixed Methods Research, 1(1), 8-22. DOI: 10.1177/2345678906290531. 
[6] Castro, F. G., Kellison, J. G., Boyd, S. J. and Kopak, A. (2010). A Methodology for Conducting Integrative Mixed Methods Research and Data analysis, Journal of Mixed Methods Research, 4 (4), $342-$ 360 .

[7] Collins, K. M. T., Onwuegbuzie, A. J., and Sutton, I. L. (2006). A model incorporating the rationale and purpose for conducting mixed methods research in special education and beyond, Learning Disabilities: A Contemporary Journal, 4 (1), 67-100.

[8] Creswell, J. W., Clak, V. L. P., Gutmann, M. L. and Hanson, W. E. (2007). Advanced Mixed Methods, available at http://www.sagepub.com/upm-data/19291_Chapter_7.pdf.

[9] Creswell, J.W., Clark, V. L. P., Gutman, M. L. and Hanson, W. E. (2003). Advanced Mixed Methods Research Designs, in A. Tashakkori and C. Teddlie (eds.), Handbook of Mixed Methods in Social and Behavioral Research, Thousand Oaks, CA: Sage.

[10] Danziger, J. N. and Kraemer, K. L. (1991). Survey Research and Multiple Operationism: The URBIS Project Methodology, In The Information Systems Research Challenge: Survey Research Methods, 3, $351-$ 371, Harvard Business School Press, Boston, MA.

[11] Dellinger, A. B., and Leech, N. L. (2007). Toward a Unified Validation Framework in Mixed Methods Research, Journal of Mixed Methods Research, 1 (4), 309-332.

[12] Driscoll, D. L., Yeboah, A. A., Salib, P., and Rupert, D. J., (2007). Merging Qualitative and Quantitative Data in Mixed Methods Research: How To and Why Not, Ecological and Environmental Anthropology, $3(1), 19-28$.

[13] Feilzer, M. Y. (2010). Doing Mixed Methods Research Pragmatically: Implications for the Rediscovery of Pragmatism as a Research Paradigm, Journal of Mixed Methods Research, 4(1), 6-16.

[14] Greene, J. C., Caracelli, V. J., and Graham, W. F. (1989). Toward a conceptual framework for mixed method evaluation designs, Educational Evaluation and Policy Analysis, 11(3), 255-274.

[15] Guba, E. G., and Lincoln, Y. S. (1994). Competing paradigms in qualitative research, in N. K. Denzin and Y. S. Lincoln (Eds.), Handbook of qualitative research, 105-117, Thousand Oaks, CA: Sage, Retrieved on $22^{\text {nd }}$ May 2012 from www.noppa.aalto.fi/noppa.

[16] Johnson, R. B., and Onwuegbuzie, A. J. (2004). Mixed Methods Research: A Research Paradigm Whose Time Has Come, Educational Researcher, 33(7), 14-26.

[17] Lee, Y. and Greene, J. (2007). The Predictive Validity of an ESL Placement Test A Mixed Methods Approach, Journal of Mixed Methods Research, 1 (4), 366-389.

[18] Morell, L. and Tan, R. J. B. (2009). Validating for Use and Interpretation: A Mixed Methods Contribution Illustrated, Journal of Mixed Methods Research, 3(3), 242-264, DOI: 10.1177/1558689809335079.

[19] Onwuegbuzie, A. J., and Johnson, R. B. (2006). The Validity Issue in Mixed Research, Research in the Schools, 13 (1), 48-63.

[20] Onwuegbuzie, A. J., Bustamante, R. M., and Nelson, J. A. (2010). Mixed Research as a Tool for Developing Quantitative Instruments, Journal of Mixed Methods Research, 4(1), 56-78.

[21] Clark, P., Huddleston, C. V. L., Churchill, S. L., Green, D. O., and Garrett, A. L. (2008). Mixed methods approaches in family science research, Journal of Family Issues, 29, 1543-1566.

[22] Pretty, J. N. (1993). Participatory Enquiry for Sustainable Agriculture, (IIED - Unpublished).

[23] Sandelowski, M., Voils, C. I., and Knafl, G. (2009). On Quantitizing, Journal of Mixed Methods Research, 3(3), 208-222.

[24] Smyth, R. (2006). Exploring Congruence between Habermasian Philosophy, Mixed-Method Research, and Managing Data Using N. Vivo, International Journal of Qualitative Methods, 5 (2), 1-11. 
[25] Tashakkori, A., and Cresswell, J. W. (2007). Editorial: The New Era of Mixed Methods, Journal of Mixed Methods Research, 1-3, DOI: 13-7. D0I.1177/2345678906293042.

[26] Tuli, F., (2010). The Basis of Distinction between Qualitative and Quantitative Research in Social Science: Reflection on Ontological, Epistemological and Methodological Perspectives, Ethiopian Journal of Education and Sciences, 6(1), 97-108, retrived from http://www.ajol.info/index.php/ejesc/article/viewFile/65384/53078.

[27] Yu, C. H., (2003). Misconceived relationships between logical positivism and quantitative research, Research Methods Forum [On-line], Retrieved on May 24th 2012 from http://creativewisdom.com/computer/sas/positivism.pdf. 